Super i or DC and RF Perfor mance of Al GaN Channel HEM at $\mathrm{Hi}$ gh Temper at ures

\begin{tabular}{|l|l|}
\hline 著者 & $\begin{array}{l}\text { HATANO Nai ko, YAFUNE Nor i masa, TOKUDA } \\
\text { H r okuni, YAMAMOTO Yoshi yuki, HASH MOTO Shi n, } \\
\text { AK TA Kat sushi, KUZUHARA Nasaaki }\end{array}$ \\
\hline $\begin{array}{l}\text { j our nal or } \\
\text { publ i cat i on t i tl e }\end{array}$ & I El CE Tr ans. El ect r oni cs \\
\hline vol une & E95- C \\
\hline page range & $1332-1336$ \\
\hline year & $2012-08$ \\
\hline URL & ht t p: //hdl . handl e. net /10098/7419 \\
\hline
\end{tabular}




\title{
Superior DC and RF Performance of AIGaN-Channel HEMT at High Temperatures
}

\author{
Maiko HATANO $^{\dagger a)}$, Student Member, Norimasa YAFUNE ${ }^{\dagger \dagger}$, Nonmember, Hirokuni TOKUDA ${ }^{\dagger}$, Member, $^{\text {, }}$ \\ Yoshiyuki YAMAMOTO $^{\dagger \dagger \dagger}$, Shin HASHIMOTO ${ }^{\dagger \dagger \dagger}$, Katsushi AKITA ${ }^{\dagger+\dagger}$, Nonmembers, \\ and Masaaki KUZUHARA ${ }^{\dagger}$, Senior Member
}

\begin{abstract}
SUMMARY This paper describes high-temperature electron transport properties of AlGaN-channel HEMT fabricated on a free-standing AIN substrate, estimated at temperatures between 25 and $300^{\circ} \mathrm{C}$. The AlGaNchannel HEMT exhibited significantly reduced temperature dependence in DC and RF device characteristics, as compared to those for the conventional AlGaN/GaN HEMT, resulting in larger values in both saturated drain current and current gain cutoff frequency at $300^{\circ} \mathrm{C}$. Delay time analyses suggested that the temperature dependence of the AlGaN-channel HEMT was primarily dominated by the effective electron velocity in the AlGaN channel. These results indicate that an AlGaN-channel HEMT fabricated on an AIN substrate is promising for high-performance device applications at high temperatures.

key words: AlGaN channel, high temperature, HEMT
\end{abstract}

\section{Introduction}

GaN-based HEMTs are expected as promising devices for high-voltage, high-frequency and high-temperature electronic applications. With an ability to exhibit extremely reduced intrinsic carrier concentration, DC characteristics of $\mathrm{AlGaN} / \mathrm{GaN}$ HEMTs at elevated temperatures have been reported by many authors [1]-[7]. Kordos et al. reported that with increasing the device temperature to more than $200^{\circ} \mathrm{C}$, the saturated drain current of a $2 \mu \mathrm{m}$ gate-length AlGaN/GaN HEMT decreased to below one half of that measured at room temperature [6]. It is evident that the temperature dependence in the DC characteristics of GaN-based HEMTs should be further improved to ensure stable device operation at high temperatures.

Recently, a novel nitride-based HEMT structure, in which $\mathrm{AlGaN}$ is used as a channel layer, has been proposed [8]-[13]. Nanjo et al. demonstrated that a drain breakdown voltage as high as $1650 \mathrm{~V}$ was achieved for an AlGaNchannel HEMT with an Al composition of $38 \%$ [9]. Tokuda et al. reported that the degradation in the drain current by increasing the device temperature from room temperature (RT) to $300^{\circ} \mathrm{C}$ was significantly suppressed within $20 \%$ by using an $\mathrm{AlGaN}$ channel with an $\mathrm{Al}$ composition of $51 \%$ [11]. However, the magnitude of the drain current at $300^{\circ} \mathrm{C}$

Manuscript received November 16, 2011.

Manuscript revised March 6, 2012

${ }^{\dagger}$ The authors are with the Graduate School of Engineering, University of Fukui, Fukui-shi, 910-8507 Japan. Japan.

The author is with Sharp Corporation, Tenri-shi, 632-8567

${ }^{+1+}$ The authors are with Sumitomo Electric Industries, Ltd., Itami-shi, 664-0016 Japan.

a)E-mail: mhatano@u-fukui.ac.jp

DOI: $10.1587 /$ transele.E95.C.1332 was still larger for the conventional AlGaN/GaN HEMT than that for the AlGaN-channel device, and no data have been reported on the high-temperature RF performance for the AlGaN-channel HEMT.

In this paper, DC and RF performance of AlGaNchannel HEMTs fabricated on an AlN substrate is presented. The maximum drain current and the current gain cutoff frequency measured at temperatures from RT to $300^{\circ} \mathrm{C}$ are compared between devices with an AlGaN channel and a $\mathrm{GaN}$ channel. The mechanism responsible for the superior performance for the developed AlGaN-channel HEMT at high temperatures is discussed.

\section{Device Fabrication}

Figure 1 shows the schematic diagram of an $\mathrm{AlGaN}$-channel HEMT fabricated on a free standing C-plane AlN substrate. Epitaxial layers were grown by metal-organic vapor phase epitaxy (MOVPE). The structure consists of a 200-nm-thick AlN buffer, an undoped $600 \mathrm{~nm}$ AlGaN channel layer with an $\mathrm{Al}$ composition of 0.26 , and an undoped $27 \mathrm{~nm}$ AlGaN barrier layer with an $\mathrm{Al}$ composition of 0.50 . Device fabrication began with mesa isolation using ICP-RIE based on $\mathrm{BCl}_{3}$ plasma. Then, the source and drain ohmic contacts were formed using a $\mathrm{Zr} / \mathrm{Al} / \mathrm{Mo} / \mathrm{Au}$ metal stack annealed at $950^{\circ} \mathrm{C}$ for $30 \mathrm{~s}$ [14]. The specific ohmic contact resistivity and the sheet resistance, estimated by transmission-linemodel (TLM) measurements were $5.0 \times 10^{-4} \Omega \mathrm{cm}^{2}$ and $4550 \Omega /$ sq, respectively. Ni/Au was used as Schottky gate metallization.

DC characteristics were measured using on-wafer DC probes for a device with a gate length $\left(L_{g}\right)$ of $6 \mu \mathrm{m}$ and a gate

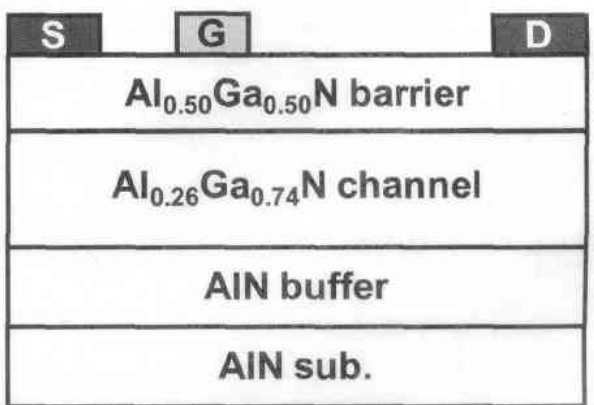

Fig.1 Schematic cross section of $\mathrm{Al}_{0.50} \mathrm{Ga}_{0.50} \mathrm{~N} / \mathrm{Al}_{0.26} \mathrm{Ga}_{0.74} \mathrm{~N}$ HEMT on AIN substrate. 
width $\left(W_{q}\right)$ of $515 \mu \mathrm{m}$. S-parameter measurements were performed using on-wafer RF probes from $10 \mathrm{MHz}$ to $4 \mathrm{GHz}$ for a device with $L_{q}=2 \mu \mathrm{m}$ and $W_{q}=2 \times 50 \mu \mathrm{m}$. A standard $\mathrm{AlGaN} / \mathrm{GaN}$ HEMT with identical electrode dimension was fabricated on a Si substrate. The thickness and $\mathrm{Al}$ composition for the $\mathrm{AlGaN}$ barrier layer were $25 \mathrm{~nm}$ and 0.25 , respectively. Since the main purpose of this work is to study the importance of channel materials, no surface passivation films were used for all the devices.

\section{Results and Discussion}

Figures 2(a) and (b) show DC drain I-V characteristics for the fabricated AlGaN-channel HEMT $\left(L_{g}=6 \mu \mathrm{m}\right.$ and $W_{g}=515 \mu \mathrm{m}$ ) measured at $25^{\circ} \mathrm{C}$ and at $300^{\circ} \mathrm{C}$, respectively. The maximum drain current defined at a gate-to-source bias voltage $\left(V_{g s}\right)$ of $2 \mathrm{~V}$ was $175 \mathrm{~mA} / \mathrm{mm}$ at $25^{\circ} \mathrm{C}$ and was $106 \mathrm{~mA} / \mathrm{mm}$ at $300^{\circ} \mathrm{C}$.

Figure 3 shows the maximum drain current as a func-

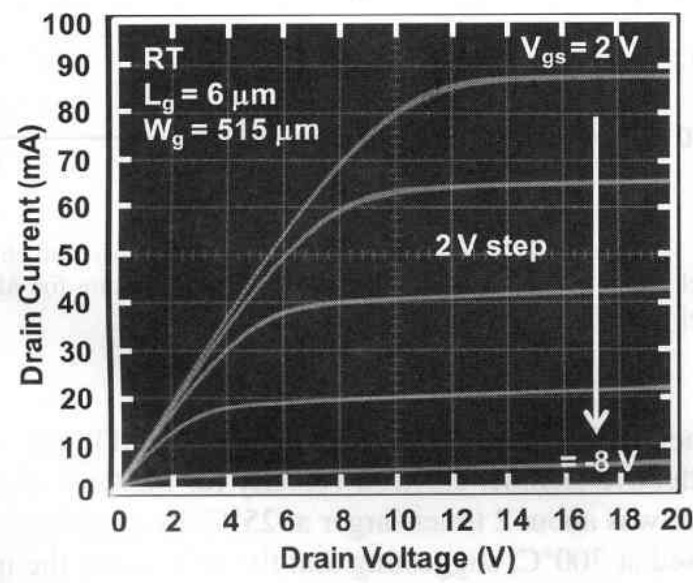

(a)

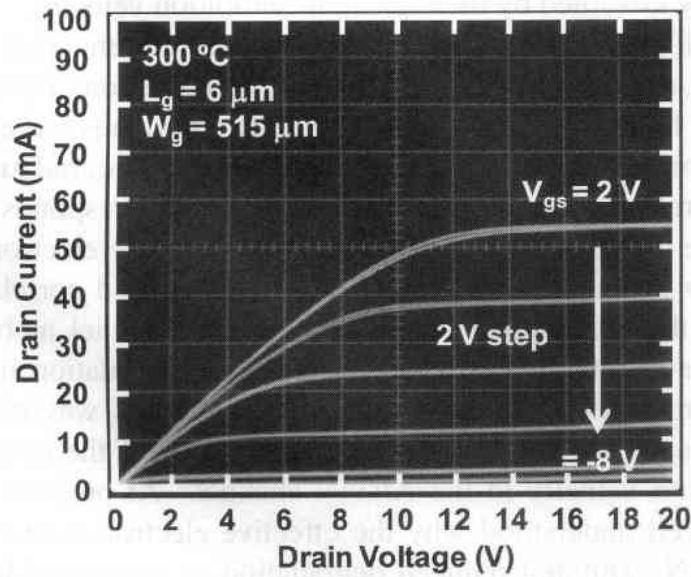

(b)

Fig. 2 Drain I-V characteristics for AlGaN-channel HEMT with $L_{q}=$ $6 \mu \mathrm{m}$ and $W_{g}=515 \mu \mathrm{m}$ at (a) RT and (b) $300^{\circ} \mathrm{C}$. tion of temperature for the AlGaN-channel HEMT and for the conventional AlGaN/GaN HEMT. The maximum drain current for the GaN-channel HEMT decreased from $281 \mathrm{~mA} / \mathrm{mm}$ at $25^{\circ} \mathrm{C}$ to $97 \mathrm{~mA} / \mathrm{mm}$ at $300^{\circ} \mathrm{C}$, corresponding to about $65 \%$ degradation. Similar degradation trend has been observed for AlGaN/GaN HEMT fabricated on a sapphire substrate, suggesting that the substrate thermal conductivity has minor influence on the comparison of drain current at high temperatures. On the other hand, the degradation for the AlGaN-channel device was only $40 \%$. Therefore, although the maximum drain current at RT was smaller for the $\mathrm{AlGaN}$ channel, its magnitude was reversed with each other at around $250^{\circ} \mathrm{C}$. At $300^{\circ} \mathrm{C}$, the maximum drain current for the $\mathrm{AlGaN}$-channel HEMT was about $10 \%$ larger than that for the GaN-channel HEMT. This is the first report demonstrating that an AlGaN-channel HEMT, having identical device dimension, shows better DC characteristics than $\mathrm{AlGaN} / \mathrm{GaN}$ HEMTs when estimated at high temperatures.

In order to investigate the mechanism for the reversal in drain current observed between $\mathrm{GaN}$ and $\mathrm{AlGaN}$ channels, temperature dependent Hall-effect measurements have been performed using the van der Pauw method. Figure 4 shows the Hall mobility measured from RT to $300^{\circ} \mathrm{C}$ for heterostructures with an $\mathrm{AlGaN}$ channel and with a conventional GaN channel. It was found that the channel mobility decreased monotonically with the increase in temperature for both channel materials, indicating that no reversal in the magnitude of channel mobility occurred between the samples at temperatures up to $300^{\circ} \mathrm{C}$.

Figure 5 shows temperature dependence of the current gain cutoff frequency for AlGaN-channel and GaN-channel HEMTs $\left(L_{g}=2 \mu \mathrm{m}\right.$ and $\left.W_{g}=100 \mu \mathrm{m}\right)$ estimated by on-wafer $\mathrm{S}$-parameter measurements. Devices were biased at $V_{g s}=0 \mathrm{~V}$ and at a drain-to-source voltage $\left(V_{d s}\right)$ of $25 \mathrm{~V}$. The current gain cutoff frequency was estimated by extrapolating current gain $\left(\mathrm{h}_{21}\right)$ using $-20 \mathrm{~dB} / \mathrm{dec}$ roll-off. S-parameters at each frequency were used after de-embedding parasitic pad capacitance and inductance [15]. The current gain cutoff frequency monotonically decreased with increasing tempera-

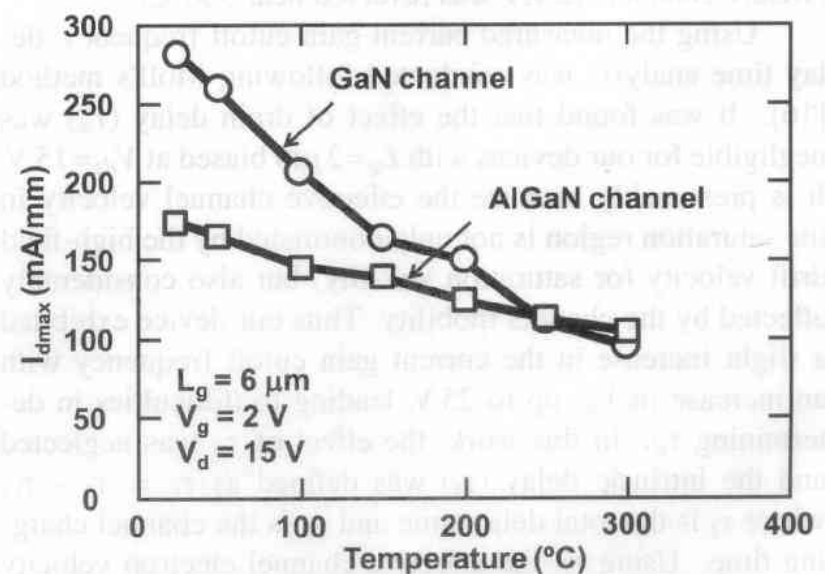

Fig. 3 Maximum drain current (Idmax) as a function of temperature for AlGaN-channel HEMT and for GaN-channel HEMT. 


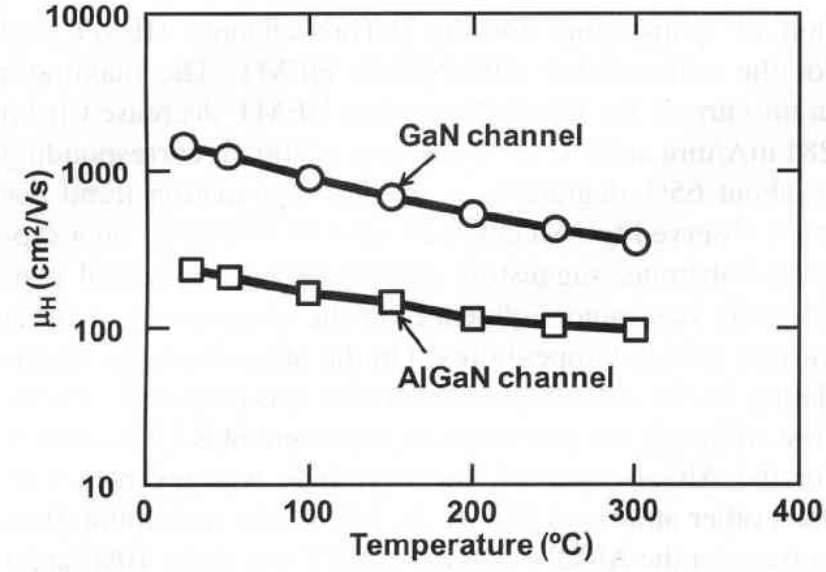

Fig. 4 Temperature dependence of Hall mobility for devices with AlGaN channel and $\mathrm{GaN}$ channel.

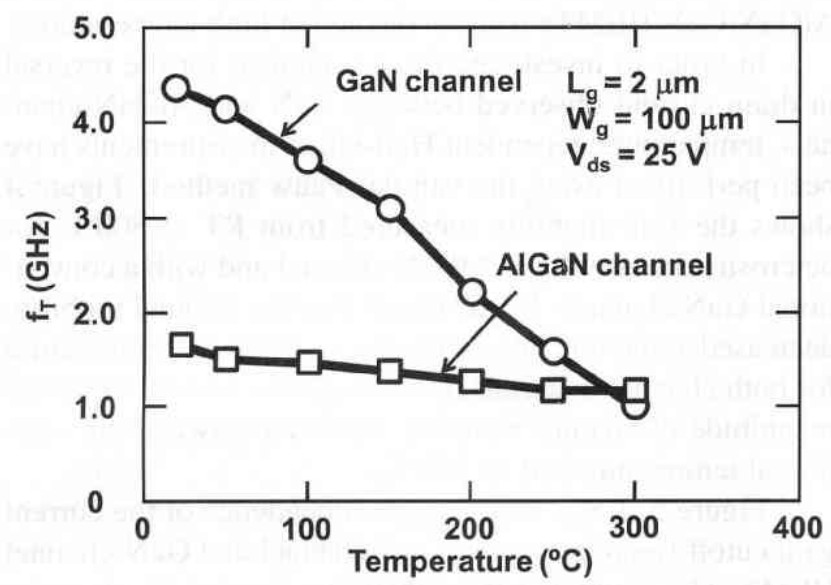

Fig. 5 Current gain cutoff frequency $\left(\mathrm{f}_{T}\right.$ ) as a function of temperature for AlGaN-channel HEMT and for GaN-channel HEMT with $L_{g}=2 \mu \mathrm{m}$ and $W_{g}=100 \mu \mathrm{m}$.

ture in both devices. However, it is obvious that the decrease ratio for the AlGaN-channel HEMT is extremely smaller than that for the GaN-channel HEMT. More interestingly, the magnitude of the current gain cutoff frequency for the $\mathrm{AlGaN}$-channel HEMT was reversed near $300^{\circ} \mathrm{C}$.

Using the measured current gain cutoff frequency, delay time analysis was conducted following Moll's method [16]. It was found that the effect of drain delay $\left(\tau_{d}\right)$ was negligible for our devices with $L_{g}=2 \mu \mathrm{m}$ biased at $V_{d s}=15 \mathrm{~V}$. It is presumably because the effective channel velocity in the saturation region is not only dominated by the high-field drift velocity (or saturation velocity) but also considerably affected by the channel mobility. Thus our device exhibited a slight increase in the current gain cutoff frequency with an increase in $V_{d s}$ up to $25 \mathrm{~V}$, leading to difficulties in determining $\tau_{d}$. In this work, the effect of $\tau_{d}$ was neglected and the intrinsic delay $\left(\tau_{i}\right)$ was defined as $\tau_{i}=\tau_{t}-\tau_{c}$, where $\tau_{t}$ is the total delay time and $\tau_{c}$ is the channel charging time. Using $\tau_{i}$, the effective channel electron velocity was derived by $L_{g} / \tau_{i}$. Table 1 shows the effective channel electron velocity estimated at 25 and $300^{\circ} \mathrm{C}$ for an $\mathrm{AlGaN}$ -
Table 1 Effective channel electron velocity of AlGaN-channel HEMT and $\mathrm{GaN}$-channel HEMT evaluated at $25^{\circ} \mathrm{C}$ and at $300^{\circ} \mathrm{C}$.

\begin{tabular}{ccc}
\hline & $\begin{array}{c}v_{\mathrm{eff}} @ 25^{\circ} \mathrm{C} \\
\left(10^{6} \mathrm{~cm} / \mathrm{s}\right)\end{array}$ & $\begin{array}{c}v_{\mathrm{eff}} @ 300^{\circ} \mathrm{C} \\
\left(10^{6} \mathrm{~cm} / \mathrm{s}\right)\end{array}$ \\
\hline AlGaN channel & 2.7 & 1.7 \\
GaN channel & 6.0 & 1.5 \\
\hline
\end{tabular}

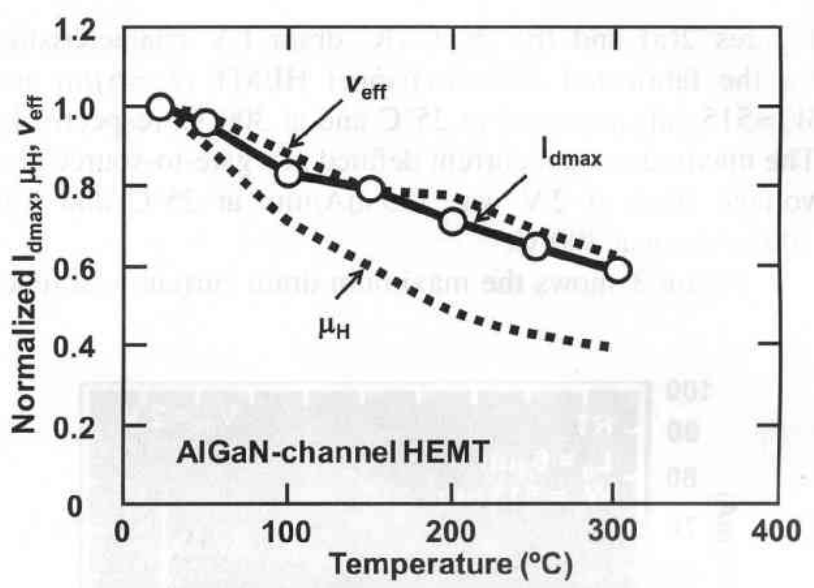

Fig. 6 Normalized maximum drain current, Hall mobility, and effective channel electron velocity $\left(v_{\text {eff }}\right)$ as a function of temperature for AlGaNchannel HEMT.

channel HEMT and for a GaN-channel HEMT. Although the effective channel electron velocity for the GaN-channel HEMT was about 2 times larger at $25^{\circ} \mathrm{C}$, its magnitude was reversed at $300^{\circ} \mathrm{C}$, suggesting that the reversal of the maximum drain current observed at high temperatures, as shown in Fig. 3, was closely related to the temperature dependence of the effective channel electron velocity that was predominantly governed by the high-field saturation velocity.

Figure 6 shows the maximum drain current, Hall mobility, and effective electron velocity as a function of temperature for the AlGaN-channel HEMT. All values were normalized to those at $25^{\circ} \mathrm{C}$. It is evident that the degradation in the drain current at elevated temperatures corresponds well to the temperature dependence of the effective electron velocity in the channel and does not show good correlation with the temperature dependence of the channel mobility. These results suggest that the reduced degradation in the maximum drain current at high temperatures was mainly dominated by the temperature dependence of the effective electron velocity in the $\mathrm{AlGaN}$ channel. At present, it is not well understood why the effective electron velocity in $\mathrm{AlGaN}$ exhibited reduced degradation as compared to the temperature dependence of the channel mobility. In our devices with $L_{g}=2 \mu \mathrm{m}$, all the channel region under the gate would not be in such enough high electric fields to allow all the channel electrons moving with a high-field (saturated) 
electron velocity. The slight deviation observed between the temperature dependences of effective electron velocity and maximum drain current, in Fig. 6, may be due to the fact that some of the channel electrons are still affected by the lowfield mobility though they are mostly accelerated by the high electric field in the channel region. To clarify the mechanism in more details, it would be desirable to perform similar experiments on shorter gate length HEMTs, where high-field transport is dominant under the whole gate region.

\section{Conclusion}

An AlGaN-channel HEMT has been fabricated on a freestanding AIN substrate and its device performance has been compared to that for a standard AlGaN/GaN HEMT. At room temperature, the conventional GaN-channel HEMT exhibited much better performances in most of the device properties, such as maximum drain current, channel electron mobility, current gain cutoff frequency, and effective electron velocity, than those for the AlGaN-channel HEMT. However, the difference in those properties was reduced with increasing the device temperature. At $300^{\circ} \mathrm{C}$, the magnitude of the maximum drain current and the current gain cutoff frequency was reversed between the two devices, showing that an AlGaN-channel HEMT is superior to a conventional $\mathrm{AlGaN} / \mathrm{GaN}$ HEMT at high temperatures. These results indicate that an AlGaN-channel HEMT on an AlN substrate is promising for high-temperature electronics applications at more than $300^{\circ} \mathrm{C}$. The superior hightemperature performance of $\mathrm{AlGaN}$-channel HEMTs is presumed to be due to the comparatively small temperature dependence in electron drift velocity at high fields.

\section{Acknowledgments}

This work was performed as a part of the project named "Development of Nitride-based Semiconductor Single Crystal Substrate and Epitaxial Growth Technology" by NEDO. This work was also supported by a grant from the Global COE Program, "Center for Electronic Devices Innovation", from the Ministry of Education, Culture, Sports, Science and Technology of Japan.

\section{References}

[1] O. Aktas, Z.F. Fan, S.N. Mohammad, A.E. Botchkarev, and H. Morkoc, "High temperature characteristics of AlGaN/GaN modulation doped field-effect transistors," Appl. Phys. Lett., vol.69, pp.3872-3874, 1996.

[2] R. Gaska, Q. Chan, J. Yang, A. Osinsky, M.A. Khan, and M.S. Shur, "High-temperature performance of AlGaN/GaN HFET's on SiC substrates," IEEE Electron Device Lett., vol.18, no.10, pp.492494, 1997.

[3] N. Maeda, T. Saitoh, K. Tsubaki, T. Nishida, and N. Kobayashi, "Superior pinch-off characteristics at $400^{\circ} \mathrm{C}$ in $\mathrm{AlGaN} / \mathrm{GaN}$ heterostructure field effect transistors," Jpn. J. Appl. Phys., vol.38, pp.L987L989, 1999.

[4] T. Egawa, H. Ishikawa, and M. Umeno, "Recessed gate AlGaN/GaN modulation-doped field-effect transistors on sapphire," Appl. Phys.
Lett., vol.76, pp.121-123, 2000.

[5] S. Arulkumaran, T. Egawa, H. Ishikawa, and T. Jimbo, "Hightemperature effects of $\mathrm{AlGaN} / \mathrm{GaN}$ high-electron-mobility transistors on sapphire and semi-insulating $\mathrm{SiC}$ substrates," Appl. Phys. Lett., vol.80, pp.2186-2188, 2002.

[6] P. Kordos, D. Donoval, M. Florovic, J. Kovac, and D. Gregusova, "Investigation of trap effects in $\mathrm{AlGaN} / \mathrm{GaN}$ field-effect transistors by temperature dependent threshold voltage analysis," Appl. Phys. Lett., vol.92, 152113, 2008.

[7] R. Cuerdo, F. Calle, A.F. Brana, Y. Cordier, M. Azize, N. Baron, S Chenot, and E. Munoz, "High temperature behavior of GaN HEMT devices on $\mathrm{Si}(111)$ and sapphire substrates," Phys. Stat. Sol. (c), vol.5, pp.1971-1973, 2008.

[8] T. Nanjo, M. Takeuchi, M. Suita, Y. Abe, T. Oishi, Y. Tokuda, and Y. Aoyagi, "First operation of AlGaN channel high electron mobility transistors," Appl. Phys. Express 1, 011101, 2008.

[9] T. Nanjo, M. Takeuchi, M. Suita, Y. Abe, T. Oishi, Y. Tokuda, and Y. Aoyagi, "Remarkable breakdown voltage enhancement in AlGaN channel HEMTs," IEDM. Tech. Dig., pp.397-400, 2007.

[10] A. Raman, S. Dasgupta, S. Rajan, J.S. Speck, and U.K. Mishira, "AlGaN channel high electron mobility transistors: Device performance and power-switching figure of merit," Jpn. J. Appl. Phys., vol.47, pp.3359-3361, 2008.

[11] H. Tokuda, M. Hatano, N. Yafune, S. Hashimoto, K. Akita, Y. Yamamoto, and M. Kuzuhara, "High Al composition AlGaNchannel high-electron-mobility transistor on AIN substrate," Appl. Phys. Express 3, 121003, 2010.

[12] M. Hatano, N. Kunishio, H. Chikaoka, J. Yamazaki, Z.B. Makhzani, N. Yafune, K. Sakuno, S. Hashimoto, K. Akita, Y. Yamamoto, and M. Kuzuhara, "Comparative high-temperature DC characterization of HEMTs with GaN and AlGaN channel layers," CS MANTECH Conf., Dig., pp.101-104, 2010.

[13] M. Hatano, J. Yamazaki, N. Yafune, S. Hashimoto, K. Akita, Y Yamamoto, and M. Kuzuhara, "High-temperature RF characterization of AlGaN-channel HEMTs," 9th Topical Workshop on Heterostructure Microelectronics (TWHM2011), Dig., pp.13-14, 2011.

[14] N. Yafune, S. Hashimoto, K. Akita, Y. Yamamoto, and M. Kuzuhara, "Low-resistive ohmic contacts for AlGaN channel high-electronmobility transistors using $\mathrm{Zr} / \mathrm{Al} / \mathrm{Mo} / \mathrm{Au}$ metal stack," Jpn. J. Appl. Phys., vol.50, 100202, 2011.

[15] Q. Fan, J.H. Leach, and H. Morkoc, "Small signal equivalent circuit modeling for AlGaN/GaN HFET: Hybrid extraction method for determining circuit elements of AlGaN/GaN HFET," Proc. IEEE, vol.98, pp.1140-1150, 2010.

[16] N. Moll, M.R. Hueschen, and A.F. Colbrie, "Pulse-doped AlGaAs/InGaAs pseudomorphic MODFET's," IEEE Trans. Electron Device., vol.35, no.7, pp.879-885, 1988.

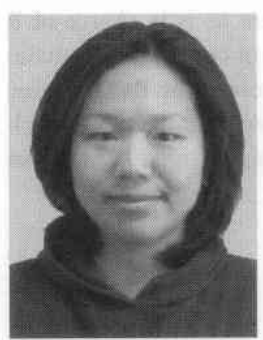

Maiko Hatano received the B.E. and M.E. degrees in Electrical and Electronics Engineering from University of Fukui, Fukui, Japan, in 2009 and 2011, respectively. She is currently working toward the Ph.D. degree in the System Design Engineering Course, University of Fukui, Fukui, Japan. 


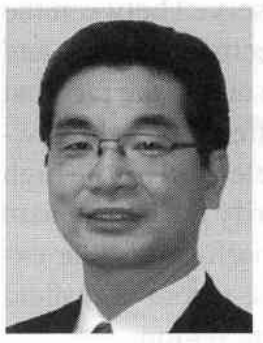

Masaaki Kuzuhara received the B.E., M.E. and $\mathrm{Ph} . \mathrm{D}$. degrees in electrical engineering from Kyoto University, Kyoto, Japan, in 1979, 1981 and 1991, respectively. He is currently a Professor in Electrical and Electronics Engineering, University of Fukui, Fukui, Japan. His research interests include III-nitride heterojunction devices for high-voltage and high-frequency applications. He is a Fellow of IEEE.

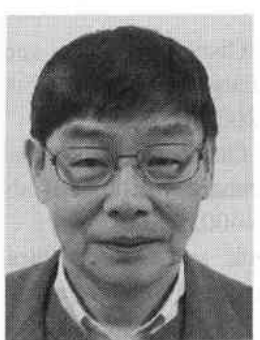

Hirokuni Tokuda received the Ph.D. degree in electronics engineering from University of Tokyo, Japan, in 1978. From 1978 to 2002, he worked for Toshiba Corp., where he had been in charge of the development of millimeter-wave HEMTs. In 2002, he moved to Murata Manufacturing Co. Ltd., where he was a general manager of Antenna Products Dept. After the retirement from Murata in 2009, he got the job at University of Fukui. His current interests are GaNbased HEMT devices and their physics.

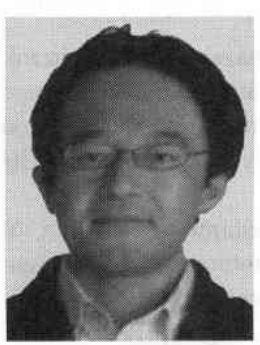

Yoshiyuki Yamamoto received the B.E. and M.E. degrees in industrial chemistry from University of Tokyo, Japan, in 1990 and 1992, respectively. He has been working for Sumitomo Electric Industries from 1992, where he is in charge of $R \& D$ for the bulk crystal growth technique and applications of wide-bandgap semiconductor materials.

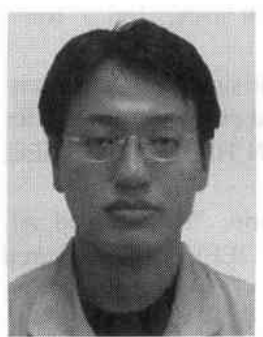

Shin Hashimoto received the M.S. degree in Physics from Osaka University, Osaka, Japan, in 2004. He is currently working in Semiconductor Technologies R\&D Laboratories, Sumitomo Electric Industries, Japan.

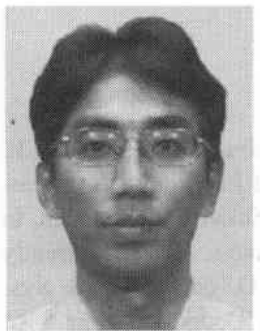

Katsushi Akita received the B.E. and M.E. degrees in physics from Kyoto University, Kyoto, Japan, in 1993 and 1995, respectively. $\mathrm{He}$ has been working for Sumitomo Electric Industries from 1995, where he is in charge of $\mathrm{R}$ \& D for epitaxial growth of compound semiconductors. In 2007, he received the Ph.D. degree in engineering from Kyoto Institute of Technology, Kyoto, Japan. He was awarded JSAP Paper Award in 2010. 